\title{
Clinicopathological prognostic indicators of survival and pathological findings in cold-stressed Florida manatees Trichechus manatus latirostris
}

\author{
Molly Martony ${ }^{1, *}$, Jorge A. Hernandez ${ }^{1}$, Martine de Wit ${ }^{2}$, Judy St. Leger ${ }^{3}$, \\ Claire Erlacher-Reid ${ }^{3}$, Jacob Vandenberg ${ }^{3}$, Nicole I. Stacy ${ }^{4}$
}

${ }^{1}$ Department of Large Animal Clinical Sciences, College of Veterinary Medicine, University of Florida, Gainesville, Florida 32608, USA ${ }^{2}$ Marine Mammal Pathobiology Laboratory, Florida Fish and Wildlife Conservation Commission, Saint Petersburg, Florida 33711, USA ${ }^{3}$ SeaWorld Orlando, Veterinary Services, Orlando, Florida 32821, USA

${ }^{4}$ Department of Comparative, Diagnostic, and Population Medicine, College of Veterinary Medicine, University of Florida, Gainesville, Florida 32608, USA

\begin{abstract}
Cold-stress syndrome (CSS) is a leading natural cause of mortality in free-ranging Florida manatees Trichechus manatus latirostris, but comprehensive investigations into blood analyte derangements and prognostic indicators in CSS are lacking. The objectives of this study were to (1) compare admission blood analyte data of manatees pre and post rehabilitation for CSS to identify clinicopathological derangements, (2) identify blood analyte prognostic indicators for survival, and (3) correlate post-mortem anatomic pathological changes with clinicopathological findings to improve the understanding of CS pathophysiology. CSS manatees admitted to a rehabilitation facility between 2007 and 2017 were included: 59 manatees with data for clinicopathological analysis ( 7 non-survivors and 49 survivors) and 14 manatees with necropsy data ( 7 with and 7 without blood analyte data). Main interpretive clinicopathological findings indicated systemic inflammation, bone marrow damage, diuresis, malnutrition, tissue necrosis, fat mobilization, hepatic impairment, acid-base imbalances, and gastrointestinal ulceration. The best diagnostically performing prognostic indicators for survival included platelet concentration, aspartate aminotransferase, calcium, and blood urea nitrogen. The main anatomic pathological findings were cutaneous lesions $(\mathrm{n}=14)$, lipid depletion $(\mathrm{n}=12)$, upper gastrointestinal ulceration and/or hemorrhage $(n=9)$, and pneumonia $(n=5)$. Based on the identified blood prognostic indicators interpreted in the context of anatomic pathological findings, multi-organ tissue injury, gastrointestinal ulceration and/or hemorrhage, and hemodynamic and platelet derangements are the presumptive major factors of CSS manatee mortality. These results contribute to the understanding of the complex CSS pathophysiology and offer the use of blood analyte prognostic indicators as a clinically applicable tool for the medical care of manatees during rehabilitation, thereby contributing to increased rehabilitation success and conservation of the Florida manatee.
\end{abstract}

KEY WORDS: Manatee - Sirenian - Cold-stress syndrome - CSS - Blood analyte - Pathology · Prognosis $\cdot$ Rehabilitation

\section{INTRODUCTION}

The Florida manatee Trichechus manatus latirostris, a subspecies of the West Indian manatee, is endemic to the subtropical coastal waters and rivers of the

${ }^{*}$ Corresponding author: mollymartony@ufl.edu southeastern USA and is currently listed as threatened in the USA (Kurth 2017), but is listed as Endangered by the International Union for Conservation of Nature Red Book (Deutsch 2008). The manatee is relatively cold intolerant due to its high thermal conductance, 
low metabolic rate, and limited ability to generate body heat (Irvine 1983, Bossart et al. 2002). These metabolic challenges necessitate migration to warm water refuges during cold seasons for survival. Continuous exposure to cold water temperatures below $20^{\circ} \mathrm{C}$ incites a complex pathophysiological cascade affecting metabolic, nutritional, and immunological functions resulting in cold-stress syndrome (CSS) (Bossart et al. 2002, 2004). Manatees affected by acute and chronic CSS are commonly admitted to rehabilitation facilities during winter months.

The clinical diagnosis of CSS is a presumptive diagnosis based on cold water temperatures in the area of discovery and characteristic clinical evidence. Exposure to cold water temperatures causes complex physiological derangements that predispose for opportunistic infections and characteristic dermatological changes such as epidermal bleaching, hyperkeratosis, pustular ulcerative dermatitis, and weight loss (Barratclough et al. 2017b, Bossart 2001, 2002). Pathological features associated with CSS include pustular dermatitis, epidermal hyperplasia, generalized emaciation with serous atrophy of fat, lymphoid depletion, enterocolitis, bronchopneumonia, and myocardial degeneration (Bossart et al. 2002, 2004). Clinical studies have reported an increased risk for thromboembolic disease, decreased immune function via reduced lymphocyte proliferation (Walsh et al. 2005, Barratclough et al. 2017b), and systemic inflammation due to changes in the acute phase proteins serum amyloid A (SAA) and albumin (Cray et al. 2013). However, only 1 observational description of basic hematology and chemistry data with CSS exists referring to leukocytosis, dehydration, and elevated lactate dehydrogenase, creatine kinase, and creatinine (Bossart 2001). Comprehensive investigations based on objective methodology into clinicopathological derangements with CSS syndrome have not been performed to date.

Quantitative descriptions of disease severity and prognostic indicators for rehabilitation outcome for CSS manatees do not exist. Qualitative descriptions of epidermal lesions in CSS manatees range from epidermal bleaching to orthokeratotic hyperkeratosis, but the significance of these lesions as it relates to disease outcome is unknown (Bossart et al. 2002, Barratclough et al. 2017b). Thromboelastography and Ddimer concentrations have been proposed as potential prognostic indicators in CSS (Barratclough et al. 2017b); however, their diagnostic performance regarding CSS has not been established. These tests are also not readily available to marine mammal rehabilitation facilities (Barratclough et al. 2017b).
Markedly increased SAA (>1200 $\mu \mathrm{g} \mathrm{ml}^{-1}$ ) has been proposed to have potential prognostic utility for manatees with generalized inflammation from various causes (Harr et al. 2006). However, this investigation did not evaluate SAA concentrations by admission cause (Harr et al. 2006).

CSS blood analyte data interpreted in the context of rehabilitation outcome can contribute to the development of prognostic indicators for CSS cases. Additionally, the establishment of prognostic indicators offers a diagnostic tool to facilitate prompt evaluation of disease severity, enhance triaging, and may direct specific clinical treatments (Dembek et al. 2014). The objectives of this study were to (1) compare admission blood analyte data of survivor manatees to their pre-release data after rehabilitation to identify clinicopathological derangements, (2) identify blood analyte prognostic indicators for survival, and (3) correlate post-mortem anatomic pathological changes in CSS manatees with clinicopathological findings to improve the understanding of CS pathophysiology.

\section{MATERIALS AND METHODS}

\subsection{Data collection}

Electronic medical records of the SeaWorld Orlando (SWO) rehabilitation facility were reviewed to identify manatee cases admitted due to CSS between 2007 and 2017. Manatees with rescue history and corresponding characteristic physical examination findings consistent with CSS, including emaciation and characteristic skin lesions, were included in this study. For each animal, morphometric data (weight, straight length, sex), case outcome (survivor vs. nonsurvivor), and complete blood count (CBC) and blood analyte data (including $19 \mathrm{CBC}$ analytes per CellDyn 3500 [Abbott] and 28 serum chemistry analytes per Olympus AU400 [Beckman Coulter]) were recorded. For survivors, paired blood data from both admission and pre-release were used. Admission blood data were defined as data from blood samples collected upon intake prior to initiation of medical treatments. Pre-release blood data were the final blood analyte data collected prior to the animal's release back into the wild. Blood analyte data included: serum electrolyte concentrations (sodium [Na], potassium $[\mathrm{K}]$, chloride $[\mathrm{Cl}], \mathrm{Na} \mathrm{K}$ ratio, calcium [Ca], and $\mathrm{Ca}$ to phosphorus [Ca:P] ratio). Serum biochemistry analysis included total protein (TP), albumin (Alb), globulins (Glob), Alb:Glob ratio, glucose (Gluc), blood urea nitrogen (BUN), creatinine (Crea), BUN: 
Crea ratio, total bilirubin (Bili), phosphorus (P), cholesterol (Chol), triglycerides (Trig), creatine kinase (CK), alkaline phosphatase (ALP), alanine aminotransferase (ALT), aspartate aminotransferase (AST), gamma-glutamyl transferase (GGT), lactate dehydrogenase (LDH), carbon dioxide $\left(\mathrm{CO}_{2}\right)$, fibrinogen, iron $(\mathrm{Fe})$; and $\mathrm{CBC}$ data (hemoglobin $[\mathrm{Hb}]$, hematocrit [Hct], red blood cell count [RBC], mean corpuscular volume $[\mathrm{MCV}]$, mean corpuscular hemoglobin $[\mathrm{MCH}], \mathrm{MCH}$ concentration $[\mathrm{MCHC}]$, red cell distribution width [RDW], platelets, mean platelet volume [MPV], nucleated red blood cells per 100 white blood cells [NRBC], absolute nucleated red blood cells $[\mathrm{nRBC}]$, erythrocyte sedimentation rate [ESR], total white blood cells [WBC], absolute band heterophils [Band], absolute heterophils [Hetero], absolute monocytes [Mono], absolute eosinophils [Eos], and absolute basophils [Baso]). For each study animal, SAA was analyzed from serum archived from admission and from pre-release samples of survivors. Archived samples were not available for all manatees at all time points; therefore, sample numbers vary slightly. Blood films stained with Wright's stain were reviewed for blood cell morphology and WBC differential counts.

Necropsy reports based on gross examinations by the Marine Mammal Pathobiology Laboratory, St. Petersburg, FL, and respective histopathology reports provided by board-certified anatomic pathologists were reviewed from non-survivors. Gross anatomic pathological and histopathological findings were summarized for each animal; these findings from each manatee were then compared to the available intake clinicopathological data.

\subsection{Data analysis}

The categorical variable (sex) was evaluated using a chi-squared test and an exact p-value was recorded. The admission and pre-release blood analytes in survivor manatees were compared using the Wilcoxon signed rank test, and median, first, and third quartiles were established due to the non-normally distributed data.

The admission morphometric and blood analyte data from surviving and non-surviving manatees was described using median, first, and third quartiles due to the non-evenly distributed data using Statistix 10 (Analytical software). The continuous data were compared using the Wilcoxon rank sum test. Blood analytes of clinical significance (SAA) or statistical significance $(p<0.01)$ were evaluated using a receiver operating characteristic (ROC) analysis which included; SAA, platelets, NRBC, BUN, TP, ALB, AST, GGT, CK, Ca, Ca:P ratio, and iron. The results were compared with the known outcome during rehabilitation (i.e. survival or mortality) of each CSS clinical case, and a ROC analysis was used to asses each variable's diagnostic performance (Greiner et al. 2000, Stacy et al. 2013). The data points were analyzed using the area under the ROC curve (AUC), and cut-off points, sensitivity, specificity, and 95\% confidence intervals were established using Med$\mathrm{Cal}^{\mathrm{R}}$ (Med Calc Software).

\section{RESULTS}

In total, 63 CSS manatees were included in the study. Blood sample data for clinicopathological analyses was obtained in 56 cases: all 49 survivors and 7 of the 14 non-survivors. The other 7 animals died before blood could be sampled, but necropsy data was available for anatomic pathology review for all 14 non-survivors (14 gross pathology reports; 12 also had histopathology reports). Mortality for CSS manatees admitted to SWO during the 10 yr study period was $20 \%$ (14 of 67 ).

Fifteen of 17 females and 34 of 39 males survived. Median length and weight were $226 \mathrm{~cm}$ (range 140$326 \mathrm{~cm}$ ) and $251 \mathrm{~kg}$ (range 73-648 kg), respectively. There was no statistical difference between length and weight ( $\mathrm{p}=0.71$ and 0.81 ) among survivors and non-survivors.

Comparison of the survivor admission blood analytes to pre-release data identified 35 statistically significant analytes $(\mathrm{p}<0.05$; Table 1 and see Table $\mathrm{S} 1$ in the Supplement at www.int-res.com/articles/suppl/ d132p085_supp.pdf). Affected markers of inflammation included elevated SAA, fibrinogen, ESR, and Glob, and lower ALP, Fe, Alb, and Alb:Glob ratio. Leukogram at admission when compared to prerelease included higher WBC and Hetero, Band, and Mono. Significantly higher erythrogram variables at admission compared to pre-release data included $\mathrm{Hb}$, Hct, RBC, NRBC, nRBC, MPV, and MCHC. Plasma chemistry analytes that were significantly higher at admission included Gluc, BUN:Crea ratio, AST, GGT, CK, LDH, P, Trig, and Chol. Analytes that were significantly lower at admission included $\mathrm{Crea}, \mathrm{Ca}$, $\mathrm{Ca}: \mathrm{P}$ ratio, $\mathrm{Na}, \mathrm{Cl}$, and $\mathrm{CO}_{2}$.

Comparison of blood analyte and morphometric admission data between surviving and non-surviving CSS manatees revealed significant analytes ( $p<$ 0.05 ) including higher platelets, $\mathrm{TP}$, and $\mathrm{Ca}$, and lower BUN, CK, and AST in survivors (Table 2, 
Table 1. Intake and pre-release blood analyte data (SI units) for survivor $(\mathrm{n}=49)$ cold-stress syndrome Florida manatees Trichechus manatus latirostris admitted to a rehabilitation facility between 2007 and 2017. Data are medians (1st and 3rd quartiles in parentheses). Significant values $(p<0.05)$ indicated in bold. (n)RBC: (nucleated) red blood cells; WBC: white blood cells; BUN: blood urea nitrogen

\begin{tabular}{|c|c|c|c|}
\hline Blood analyte & Admission & Pre-release & $\mathrm{p}$ \\
\hline Hemoglobin $\left(\mathrm{g}^{-1}\right)$ & $124(113,137)$ & $107(101,113)$ & $<0.01$ \\
\hline Hematocrit $\left(\mathrm{l} \mathrm{l}^{-1}\right)$ & $0.37(0.33,0.41)$ & $0.32(0.30,0.34)$ & $<0.01$ \\
\hline RBC count $\left(\times 10^{12} 1^{-1}\right)$ & $3.10(2.73,3.32)$ & $2.66(2.51,2.80)$ & $<0.01$ \\
\hline Mean corpuscular volume (fl) & $118(113,123)$ & $118(115,124)$ & 0.17 \\
\hline Mean corpuscular hemoglobin (pg) & $40.4(38.8,42.2)$ & $40.3(38.7,42.15)$ & 0.21 \\
\hline Mean corpuscular hemoglobin concentration $\left(\mathrm{g} \mathrm{l}^{-1}\right)$ & $342(337,345)$ & $339(333,343)$ & $<0.01$ \\
\hline Red cell distribution width (\%) & $16.75(16.02,17.37)$ & $16.35(15.72,17.37)$ & 0.15 \\
\hline Platelet count $\left(\times 10^{9} \mathrm{l}^{-1}\right)$ & $406(287,530)$ & $354(301,428)$ & 0.02 \\
\hline Mean platelet volume (fl) & $4.68(4.04,5.31)$ & $4.48(4.10,4.74)$ & 0.01 \\
\hline nRBC per 100 WBCs (\%) & $3(0,12)$ & $0(0,1)$ & $<0.01$ \\
\hline $\mathrm{nRBC}\left(\times 10^{9} \mathrm{l}^{-1}\right)$ & $0.42(0,1.80)$ & $0(0,0.02)$ & $<0.01$ \\
\hline Total WBC $\left(\times 10^{9} 1^{-1}\right)$ & $13.30(9.00,18.35)$ & $7.49(6.03,8.60)$ & $<0.01$ \\
\hline Band heterophils $\left(\times 10^{9} \mathrm{l}^{-1}\right)$ & $0.46(0.10,1.33)$ & $0.06(0,0.10)$ & $<0.01$ \\
\hline Heterophils $\left(\times 10^{9} \mathrm{l}^{-1}\right)$ & $8.19(4.78,10.91)$ & $3.66(3.13,4.32)$ & $<0.01$ \\
\hline Lymphocytes $\left(\times 10^{9} \mathrm{l}^{-1}\right)$ & $2.16(1.60,3.28)$ & $3.05(1.97,3.78)$ & 0.02 \\
\hline Monocytes $\left(\times 10^{9} \mathrm{l}^{-1}\right)$ & $1.40(0.70,2.13)$ & $0.47(0.37,0.68)$ & $<0.01$ \\
\hline Eosinophils $\left(\times 10^{9} \mathrm{l}^{-1}\right)$ & $0(0,0.18)$ & $0(0,0.07)$ & 0.18 \\
\hline Basophils $\left(\times 10^{9} \mathrm{l}^{-1}\right)$ & $0(0,0)$ & $0(0,0.06)$ & 0.07 \\
\hline Erythrocyte sedimentation rate $\left(\mathrm{mm} \mathrm{h}^{-1}\right)$ & $55(34,80)$ & $35(22,50)$ & $<0.01$ \\
\hline Glucose $\left(\mathrm{mmol} \mathrm{l}^{-1}\right)$ & $5.94(4.97,7.83)$ & $3.66(3.11,4.05)$ & $<0.01$ \\
\hline BUN (mmol l-1) & $3.92(3.21,5.35)$ & $4.28(3.92,5.35)$ & 0.47 \\
\hline Creatinine $\left(\mu \mathrm{mol} \mathrm{l}{ }^{-1}\right)$ & $114.9(88.4,132.6)$ & $185.6(141.4,203.3)$ & $<0.01$ \\
\hline BUN:creatinine ratio & $40.38(26.92,51.39)$ & $25.84(22.43,32.81)$ & $<0.01$ \\
\hline Bilirubin $\left(\mu \mathrm{mol} \mathrm{l^{-1 }}\right)$ & $1.71(1.71,1.71)$ & $1.71(1.71,1.71)$ & 0.75 \\
\hline Cholesterol $\left(\mathrm{mmol} \mathrm{l}^{-1}\right)$ & $8.17(6.07,9.06)$ & $3.44(3.14,4.51)$ & $<0.01$ \\
\hline Triglycerides $\left(\mathrm{mmol} \mathrm{l}^{-1}\right)$ & $1.16(0.72,1.68)$ & $0.82(0.68,1.03)$ & 0.01 \\
\hline Total protein $\left(\mathrm{g} \mathrm{l}^{-1}\right)$ & $74(71,79)$ & $74(70,79)$ & 0.67 \\
\hline Albumin $\left(\mathrm{g}^{-1}\right)$ & $39(36,43)$ & $47(45,51)$ & $<0.01$ \\
\hline Globulin $\left(\mathrm{g} \mathrm{l}^{-1}\right)$ & $34(31,41)$ & $26(24,30)$ & $<0.01$ \\
\hline Albumin: globulin ratio & $1.15(0.91,1.37)$ & $1.83(1.55,2.09)$ & $<0.01$ \\
\hline Alkaline phosphatase $\left(\mu \mathrm{kat}^{-1}\right)$ & $1.07(0.89,1.22)$ & $1.49(1.17,1.75)$ & $<0.01$ \\
\hline Alanine aminotransferase $\left(\mu \mathrm{kat} \mathrm{l}^{-1}\right)$ & $0.18(0.08,0.23)$ & $0.13(0.10,0.18)$ & 0.42 \\
\hline Aspartate aminotransferase ( $\mu$ kat $1^{-1}$ ) & $0.15(0.12,0.23)$ & $0.10(0.08,0.12)$ & $<0.01$ \\
\hline Gamma-glutamyl transferase $\left(\mu \mathrm{kat}^{-1}\right.$ ) & $0.82(0.68,0.94)$ & $0.67(0.62,0.73)$ & $<0.01$ \\
\hline Creatine kinase $\left(\mu \mathrm{kat}^{-1}\right)$ & $10.19(6.46,26.10)$ & $4.53(2.67,7.57)$ & $<0.01$ \\
\hline Lactate dehydrogenase ( $\mu$ kat $\mathrm{l}^{-1}$ ) & $9.25(6.50,15.88)$ & $5.21(4.12,7.28)$ & $<0.01$ \\
\hline Calcium $\left(\mathrm{mmol} \mathrm{l}^{-1}\right)$ & $2.45(2.35,2.62)$ & $2.60(2.53,2.69)$ & $<0.01$ \\
\hline Phosphorus (mmol l-1) & $1.90(1.61,2.26)$ & $1.55(1.35,1.80)$ & $<0.01$ \\
\hline Calcium:phosphorus ratio & $1.66(1.40,2.06)$ & $2.20(1.83,2.47)$ & $<0.01$ \\
\hline Sodium $\left(\mathrm{mmol} \mathrm{l}^{-1}\right)$ & $142(139,144)$ & $148(146,149)$ & $<0.01$ \\
\hline Potassium $\left(\mathrm{mmol} \mathrm{l}^{-1}\right)$ & $4.3(4.0,4.9)$ & $4.5(4.2,4.7)$ & 0.79 \\
\hline Sodium:potassium ratio & $32(28,36)$ & $32(30,36)$ & 0.37 \\
\hline Chloride $\left(\mathrm{mmol} \mathrm{l}^{-1}\right)$ & $90(87,93)$ & $93(92,97)$ & $<0.01$ \\
\hline Carbon dioxide $\left(\mathrm{mmol} \mathrm{l}^{-1}\right)$ & $37(32,42)$ & $44(38,47)$ & $<0.01$ \\
\hline Iron $\left(\mu \mathrm{mol} \mathrm{l}{ }^{-1}\right)$ & $7.52(5.37,10.74)$ & $24.34(18.44,26.67)$ & $<0.01$ \\
\hline Fibrinogen $\left(\mu \mathrm{mol} \mathrm{l}^{-1}\right)$ & $8.11(7.14,8.50)$ & $7.26(6.70,7.76)$ & 0.04 \\
\hline Serum amyloid $\mathrm{A}\left(\mathrm{mg} \mathrm{l}^{-1}\right)$ & $170(148,191)$ & $1(0.5,3)$ & $<0.01$ \\
\hline
\end{tabular}

Table S2 in the Supplement). The data points with the highest AUC $(\geq 0.778)$ to predict survival were platelets, AST, Ca, and BUN (Table 3, Fig. 1, Table S3 in the Supplement). The positive and negative predictive values were estimated based on the survivability proportions to model the diagnostic performance (Table S4 in the Suppplement). Positive predictive values demonstrate that selected cut-off points for platelets $\left(>301 \times 10^{9} \mathrm{l}^{-1}\right)$, AST $\left(\leq 0.20 \mu \mathrm{kat} \mathrm{l}^{-1}\right)$, calcium $\left(>2.33 \mathrm{mmol} \mathrm{l}^{-1}\right)$, or BUN $\left(\leq 7.14 \mathrm{mmol} \mathrm{l}^{-1}\right)$ can predict survival in $\geq 96 \%$ of CSS cases (Table S4 [SI units], Table S5 [CU] in the Supplement).

Frequent anatomic pathological findings identified grossly in non-surviving CSS manatees included 14 
Table 2. Admission blood analyte data (SI units) of survivor $(\mathrm{n}=49)$ and non-survivor $(\mathrm{n}=7)$ cold-stress syndrome Florida manatees Trichechus manatus latirostris admitted to rehabilitation between 2007 and 2017. Data are medians (1st and 3rd quartiles). Significant values $(\mathrm{p}<0.05)$ indicated in bold. Abbreviations as in Table 1

\begin{tabular}{|c|c|c|c|}
\hline Blood analyte & Survivors & Non-survivors & $\mathrm{p}$ \\
\hline Hemoglobin $\left(\mathrm{g} \mathrm{l}^{-1}\right)$ & $124(113,137)$ & $113(97,128)$ & 0.09 \\
\hline Hematocrit $\left(\mathrm{l} \mathrm{l}^{-1}\right)$ & $0.37(0.33,0.41)$ & $0.34(0.29,0.36)$ & 0.11 \\
\hline RBC count $\left(\times 10^{12} \mathrm{l}^{-1}\right)$ & $3.10(2.73,3.32)$ & $2.98(2.33,3.16)$ & 0.20 \\
\hline Mean corpuscular volume (fl) & $118(113,123)$ & $118(112,121)$ & 0.64 \\
\hline Mean corpuscular hemoglobin (pg) & $40.4(38.3,42.25)$ & $40.2(38.15,41.45)$ & 0.60 \\
\hline Mean corpuscular hemoglobin concentration $\left(\mathrm{g} \mathrm{l}^{-1}\right)$ & $342(337,345)$ & $342(335,353)$ & 0.69 \\
\hline Red cell distribution width (\%) & $16.7(16,17.35)$ & $16.9(16.70,20.10)$ & 0.05 \\
\hline Platelet count $\left(\times 10^{9} \mathrm{l}^{-1}\right)$ & $399(289,522)$ & $189(75,301)$ & $<0.01$ \\
\hline Mean platelet volume (fl) & $4.68(4.05,5.29)$ & $4.55(3.77,6.53)$ & 0.93 \\
\hline nRBC per $100 \mathrm{WBC}(\%)$ & $3.50(0,12.5)$ & $26(4.75,81.25)$ & 0.06 \\
\hline $\mathrm{nRBC}\left(\times 10^{9} \mathrm{l}^{-1}\right)$ & $0.42(0,1.79)$ & $1.35(0.12,6.55)$ & 0.20 \\
\hline Total WBC $\left(\times 10^{9} \mathrm{l}^{-1}\right)$ & $13.3(9.0,18.3)$ & $11.1(10.2,13.0)$ & 0.30 \\
\hline Band heterophils $\left(\times 10^{9} \mathrm{l}^{-1}\right)$ & $0.46(0.10,1.33)$ & $1.84(0,2.34)$ & 0.21 \\
\hline Heterophils $\left(\times 10^{9} \mathrm{l}^{-1}\right)$ & $8.19(4.78,10.91)$ & $6.76(0.24,8.44)$ & 0.20 \\
\hline Lymphocytes $\left(\times 10^{9} \mathrm{l}^{-1}\right)$ & $2.16(1.60,3.28)$ & $2.0(1.22,3.90)$ & 0.76 \\
\hline Monocytes $\left(\times 10^{9} \mathrm{l}^{-1}\right)$ & $1.40(0.70,2.13)$ & $1.46,(0.67,1.95)$ & 0.93 \\
\hline Eosinophils $\left(\times 10^{9} \mathrm{l}^{-1}\right)$ & $0(0,0.18)$ & $0.18(0.10,0.24)$ & 0.08 \\
\hline Basophils $\left(\times 10^{9} 1^{-1}\right)$ & $0(0,0)$ & $0(0,0)$ & 1.00 \\
\hline Erythrocyte sedimentation rate $\left(\mathrm{mm} \mathrm{h}^{-1}\right)$ & $56(34,80)$ & $63(35,73)$ & 0.78 \\
\hline Glucose $\left(\mathrm{mmol} \mathrm{l}^{-1}\right)$ & $5.94(4.94,7.83)$ & $6.88(4.61,7.83)$ & 1.00 \\
\hline BUN $\left(\mathrm{mmol} \mathrm{l}^{-1}\right)$ & $3.92(3.21,5.35)$ & $7.85(4.28,9.99)$ & 0.01 \\
\hline Creatinine $\left(\mu \mathrm{mol} \mathrm{l}^{-1}\right)$ & $114.9(88.4,132.6)$ & $141.4(97.2,176.8)$ & 0.14 \\
\hline BUN:creatinine ratio & $40.38(26.92,53.10)$ & $66.51(46.44,77.09)$ & 0.07 \\
\hline Bilirubin $\left(\mu \mathrm{mol} \mathrm{l} \mathrm{l}^{-1}\right)$ & $1.71(1.71,1.71)$ & $1.71(1.71,1.71)$ & 0.25 \\
\hline Cholesterol (mmol l-1) & $8.16(6.19,9.04)$ & $6.53(5.36,8.65)$ & 0.37 \\
\hline Triglycerides $\left(\mathrm{mmol} \mathrm{l}^{-1}\right)$ & $1.16(0.72,1.68)$ & $1.53(0.73,2.12)$ & 0.44 \\
\hline Total protein $\left(\mathrm{g} \mathrm{l}^{-1}\right)$ & $74(71,78)$ & $64(53,77)$ & 0.03 \\
\hline Albumin $\left(\mathrm{g} \mathrm{l}^{-1}\right)$ & $39(36,43)$ & $35(25,37)$ & 0.05 \\
\hline Globulin $\left(\mathrm{g} \mathrm{l}^{-1}\right)$ & $33(31,41)$ & $31(27,36)$ & 0.25 \\
\hline Albumin:globulin ratio & $1.15(0.91,1.36)$ & $1.19(0.80,1.30)$ & 0.69 \\
\hline Alkaline phosphatase $\left(\mu k a t l^{-1}\right)$ & $1.07(0.88,1.22)$ & $1.07(0.70,2.04)$ & 0.81 \\
\hline Alanine aminotransferase $\left(\mu \mathrm{kat}^{-1}\right)$ & $0.13(0.08,0.23)$ & $0.17(0.08,0.20)$ & 0.77 \\
\hline Aspartate aminotransferase $\left(\mu\right.$ kat $1^{-1}$ ) & $0.15(0.12,0.23)$ & $0.33(0.23,0.43)$ & $<0.01$ \\
\hline Gamma-glutamyl transferase $\left(\mu \mathrm{kat} \mathrm{l}^{-1}\right)$ & $0.82(0.68,0.93)$ & $1.30(0.65,1.42)$ & 0.08 \\
\hline Creatine kinase $\left(\mu\right.$ kat $\left.^{-1}\right)$ & $10.69(6.48,25.85)$ & $45.82(13.89,82.35)$ & 0.03 \\
\hline Lactate dehydrogenase ( $\mu \mathrm{kat}^{-1}$ ) & $9.35(6.50,15.76)$ & $13.81(9.82,18.54)$ & 0.06 \\
\hline Calcium $\left(\mathrm{mmol} \mathrm{l}^{-1}\right)$ & $2.45(2.32,2.62)$ & $2.25(2.12,2.32)$ & $<0.01$ \\
\hline Phosphorus (mmol l-1) & $1.90(1.63,2.29)$ & $1.90(1.77,2.61)$ & 0.46 \\
\hline Calcium:phosphorus ratio & $1.27(1.07,1.59)$ & $1.11(0.86,1.24)$ & 0.08 \\
\hline Sodium $\left(\mathrm{mmol} \mathrm{l}^{-1}\right)$ & $142(139,144)$ & $133(125,145)$ & 0.21 \\
\hline Potassium $\left(\mathrm{mmol} \mathrm{l}^{-1}\right)$ & $4.3(4.1,4.9)$ & $5.2(4.0,5.9)$ & 0.12 \\
\hline Sodium:potassium ratio & $32(28,35)$ & $28(22,33)$ & 0.12 \\
\hline Chloride $\left(\mathrm{mmol} \mathrm{l}^{-1}\right)$ & $91(87,92)$ & $85(78,98)$ & 0.29 \\
\hline Carbon dioxide $\left(\mathrm{mmol} \mathrm{l}^{-1}\right)$ & $37(32,42)$ & $33(24,46)$ & 0.26 \\
\hline Iron $\left(\mu \mathrm{mol} \mathrm{l}{ }^{-1}\right)$ & $7.43(5.24,10.65)$ & $3.94(2.86,9.49)$ & 0.08 \\
\hline Fibrinogen $\left(\mu \mathrm{mol} \mathrm{l}^{-1}\right)$ & $7.70(6.91,8.50)$ & $6.62(4.65,8.57)$ & 0.19 \\
\hline Serum amyloid $\mathrm{A}\left(\mathrm{mg} \mathrm{l}^{-1}\right)$ & $170(149,191)$ & $148(145,186)$ & 0.32 \\
\hline
\end{tabular}

of 14 cutaneous lesions (bleaching, ulceration), 12 of 14 lipid depletion or evidence of starvation (flattening dorsoventrally, fat depletion, serous fat atrophy), 10 of 14 pulmonary edema, 9 of 14 gastrointestinal hemorrhage or ulceration (stomach or small intestine), 4 of 14 skeletal muscle necrosis or abscessation, and 4 of 14 hepatic congestion. Frequent findings identified on histopathological reports included 11 of 12 cutaneous lesions (epidermal ulceration, hyperplasia, dermatitis), 7 of 12 pancreatic zymogen depletion due to starvation, 7 of 12 intravascular thrombosis, 6 of 12 gastrointestinal hemorrhage or ulceration, 5 of 12 pneumonia, and 5 of 12 cerebral meningeal edema (Table S6 in the Supplement). 
Table 3. Cut-off points (SI units), sensitivity, specificity, area under the curve (AUC), and confidence intervals (CI) for identification of cold-stressed syndrome Florida manatees Trichechus manatus latirostris that survived after admission to rehabilitation. Blood analytes with different superscripts $(a, b)$ are different $(p<0.05)$. Abbreviations as in Table 1

\begin{tabular}{|c|c|c|c|c|c|}
\hline Blood analyte & Cut-off point & Sensitivity & Specificity & AUC & $95 \% \mathrm{CI}$ \\
\hline Platelet count $\left(\times 10^{9} \mathrm{l}^{-1}\right)$ & $>301$ & 72.9 & 85.7 & $0.810^{\mathrm{a}, \mathrm{b}}$ & $0.681-0.903$ \\
\hline Aspartate aminotransferase $\left(\mu \mathrm{kat}^{-1}\right)$ & $\leq 0.20$ & 75.5 & 85.7 & $0.810^{\mathrm{a}, \mathrm{b}}$ & $0.684-0.903$ \\
\hline Calcium $\left(\mathrm{mmol} \mathrm{l}^{-1}\right)$ & $>2.33$ & 75.5 & 85.7 & $0.805^{\mathrm{a}, \mathrm{b}}$ & $0.677-0.898$ \\
\hline BUN $\left(\mathrm{mmol} \mathrm{l}^{-1}\right)$ & $\leq 7.14$ & 95.9 & 71.4 & $0.778^{\mathrm{b}}$ & $0.647-0.878$ \\
\hline Total protein $\left(\mathrm{g} \mathrm{l}^{-1}\right)$ & $>68$ & 87.8 & 71.4 & $0.749^{\mathrm{a}, \mathrm{b}}$ & $0.615-0.855$ \\
\hline Creatine kinase $\left(\mu \mathrm{kat}^{-1}\right)$ & $\leq 26.62$ & 79.6 & 71.4 & $0.743^{\mathrm{a}, \mathrm{b}}$ & $0.609-0.851$ \\
\hline nRBC per $100 \mathrm{WBC}(\%)$ & $\leq 35$ & 93.5 & 50.0 & $0.737^{\mathrm{a}, \mathrm{b}}$ & $0.597-0.850$ \\
\hline Albumin $\left(\mathrm{g} \mathrm{l}^{-1}\right)$ & $>37$ & 65.3 & 85.7 & $0.723^{\mathrm{a}, \mathrm{b}}$ & $0.587-0.834$ \\
\hline BUN:creatinine ratio & $\leq 45.43$ & 65.3 & 85.7 & $0.711^{\mathrm{b}}$ & $0.484-0.938$ \\
\hline Calcium:phosphorus ratio & $>1.24$ & 55.1 & 85.7 & $0.706^{\mathrm{a}, \mathrm{b}}$ & $0.537-0.874$ \\
\hline Iron $\left(\mu \mathrm{mol} \mathrm{l} \mathrm{l}^{-1}\right)$ & $>5.19$ & 75.0 & 71.4 & $0.704^{\mathrm{a}, \mathrm{b}}$ & $0.565-0.819$ \\
\hline Gamma-glutamyl transferase $\left(\mu\right.$ kat $\left.\mathrm{l}^{-1}\right)$ & $\leq 0.94$ & 87.8 & 71.4 & $0.701^{\mathrm{a}, \mathrm{b}}$ & $0.564-0.816$ \\
\hline Serum amyloid A $\left(\mathrm{mg} \mathrm{l}^{-1}\right)$ & $>150$ & 72.1 & 66.7 & $0.626^{\mathrm{a}}$ & $0.476-0.760$ \\
\hline
\end{tabular}

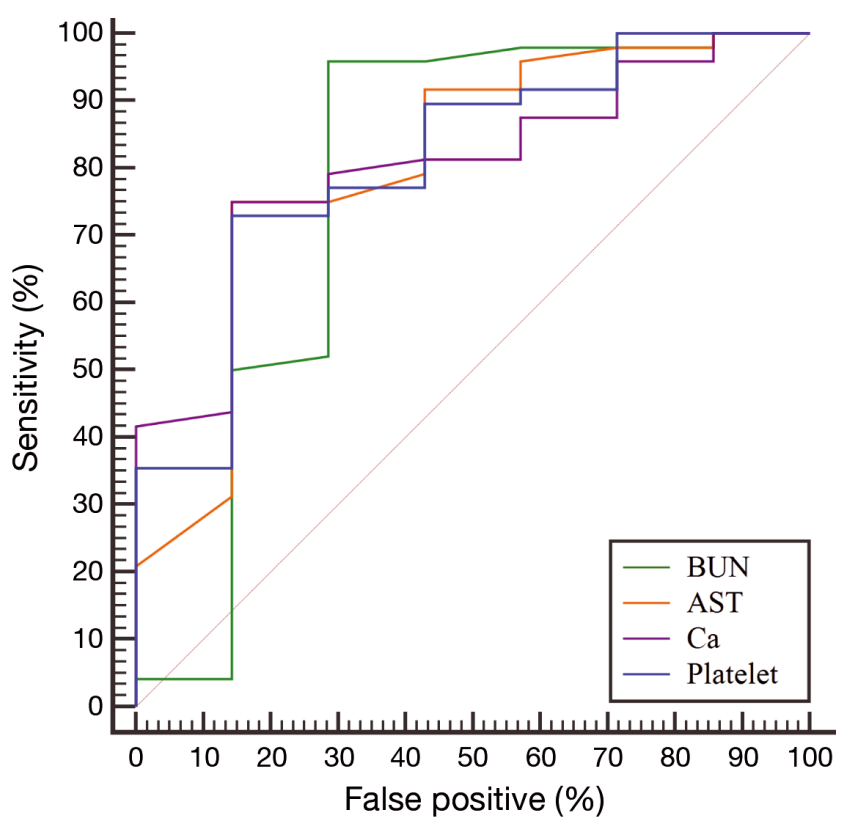

Fig. 1. Diagnostic performance of 4 blood analytes with the highest area under the curve in cold-stress syndrome manatees at various cut-off points: platelets $\left(>301 \times 10^{9} \mathrm{l}^{-1}\right)$, aspar-

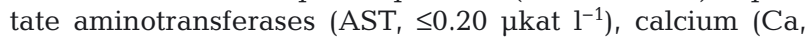
$\left.>2.33 \mathrm{mmol} \mathrm{l}^{-1}\right)$, blood urea nitrogen $\left(\mathrm{BUN}, \leq 7.14 \mathrm{mmol} \mathrm{l}^{-1}\right.$ )

\section{DISCUSSION}

This study reports comprehensive CSS manatee blood analyte data using objective analytical methodology to evaluate this information in the context of rehabilitation outcome and anatomic pathological findings. These data further the understanding of complex pathophysiological mechanisms of CSS syndrome and their clinicopathological manifestation.
This study also established prognostic indicators in CSS manatees that will facilitate prompt clinical assessment of disease severity.

The identified changes in leukogram inflammatory markers of CSS manatees at admission were characteristic for systemic inflammation in marine mammals. The anatomic pathological features indicative of inflammatory disease also followed previous studies of both CSS humans and manatees (Bossart et al. 2002, Scaravilli et al. 2012). Immunosuppressive mechanisms generally are thought to predispose CSS manatees to opportunistic infections, as evidenced by lymphoid depletion in spleen and lymph nodes described in this $(\mathrm{n}=3)$ and previous studies (Bossart et al. 2002, 2004). Leukogram inflammatory markers were not predictors of survival in CSS manatees. This was anticipated since a previous study of inflammatory disease in manatees documented the poor diagnostic utility of the manatee leukogram, which reportedly responds similarly to domestic cattle (Harr et al. 2006). Also, their poor performance as prognostic indicators may suggest that the inflammatory response is confounded during hypothermia, delaying fully active inflammatory disease severity until reactivation of the immune system is completed after rewarming, as described in humans (Scaravilli et al. 2012). Inflammatory diseases in humans affected by hypothermia, such as pneumonia, are typically diagnosed during rewarming or upon normalization of the body temperature (Scaravilli et al. 2012). In some cardiovascular and neurological conditions or procedures, hypothermia is even medically induced, in part to mitigate inflammatory-mediated tissue injury (Bernard \& Buist 2003, Deng et al. 2003). Therefore, identification of severely ill CSS manatees 
via changes in inflammatory markers may not be evident at admission bloodwork but may become overt at a later time point during or after rewarming.

Although changes in inflammatory hematological analytes were statistically significant when admission and pre-release data were compared, the magnitude of change was not always consistent with a clinically obvious marine mammal inflammatory response as characterized by other non-hematological inflammatory analytes (Harvey et al. 2007, 2009, Reidarson 2008). This finding may be associated with CSS-mediated immunosuppression and/or other confounding effects. Comparing CSS manatee leukograms to healthy-free ranging manatee reference ranges by Harvey et al. (2009), inflammatory leukograms were evident in 24 of 56 CSS manatees. Additionally, CSS-mediated lymphoid depletion in manatees (Bossart et al. 2002) or bone marrow suppression as reported in humans, may further suppress the manatees' immune response (Mallet 2002). Similarly, determination of disease severity may be impaired in human accidental hypothermia cases until rewarming and reactivation of the immune system has taken place (Scaravilli et al. 2012). Thus, leukocyte data, similar to SAA as discussed below, collected after rewarming in CSS manatees may be more diagnostically useful than admission data.

Platelets appear to play an important role in the pathophysiology of cold stress and as a prognostic indicator in CSS manatees. Platelet concentrations differed between both admission and pre-release data, and between survivors and non-survivors during rehabilitation. Platelets were significantly higher at admission compared to pre-release, although at both time points, values were within species-specific reference ranges (Bossart et al. 2001). When comparing CSS manatee to healthy free-ranging manatee reference ranges, the majority of non-surviving manatees, specifically $85.7 \%$ (6 of 7 ), were thrombocytopenic at admission, therefore platelets were useful as a prognostic indicator. Hypothermia-associated thrombocytopenia in humans has been linked to sequestration in the liver and spleen, bone marrow suppression, or disseminated intravascular coagulation (DIC) (Mallet 2002). In manatees, the normally small splenic size likely limits the extent of possible splenic sequestration; however, 1 manatee exhibited splenomegaly and liver swelling grossly, and another exhibited splenic congestion histopathologically, although both of these animals had clinically normal platelet concentrations.

Bone marrow damage appears to play a role in CSS manatees as evidenced by the inappropriate rubri- cytosis identified in the present study. Similar to reports in hypothermic humans, low platelet concentrations likely result from bone marrow damage (Rosenkranz 1985). In addition to thrombocytopenia, hypothermia-induced coagulopathies develop because cold temperatures directly inhibit the temperature-dependent enzymatic activity of the extrinsic and intrinsic pathways of the clotting cascade, and facilitate platelet aggregation and thrombosis due to impartment of prostacyclin (Mikhailidis et al. 1983, Mallet 2002). Platelet dysfunction mediated by the inhibition of thromboxane B2 in hypothermic humans reportedly is reversible upon rewarming (Valeri et al. 1987). In the present study, manatees exhibited intravascular thrombosis and hemorrhage histopathologically in the skin and lungs (dermal intravascular thrombosis 7 of 12, dermal hemorrhage 2 of 12, pulmonary intravascular thrombosis or hemorrhage 2 of 12).

Previous studies of CSS manatees proposed a mechanism of hypercoagulability and DIC in $56 \%$ of CSS manatees (Barratclough et al. 2017a). As such, thromboelastography (TEG) and D-dimer concentrations were suggested as potential prognostic indicators in CSS syndrome (Barratclough et al. 2017b). However, the performance of TEG as a prognostic indicator was impossible to be established in that study since all of the animals with available TEG data survived, and D-dimer use as a prognostic indictor was proposed via observation (Barratclough et al. 2017b). Also, such diagnostics are not readily available in marine mammal rehabilitation facilities and need to be sent out to specialized diagnostic laboratories. Platelets, however, are easily assessed in rehabilitation settings by blood film evaluation and/or manual or automated platelet counts: their role in both DIC and the pathophysiology of CSS supports their assessment as an important prognostic indicator. In a study of hypothermia in dogs, the lowest platelet count was observed in an animal with the lowest core body temperature, and platelets recovered to normal concentrations with rewarming (Yoshihara et al. 1985). Therefore, an additional consideration for thrombocytopenia in CSS manatees may be a correlation to the severity of hypothermia at the time of blood collection, although further study would be warranted to confirm this assumption.

Hemoconcentration as evidenced by increased erythrocyte indices at admission was apparent compared to pre-release data. Hypothermia-induced hemoconcentration is mediated by the loss of plasma to the extravascular space due to increased vascular permeability and cold-renal diuresis in humans 
(Mallet 2002). For every $1^{\circ} \mathrm{C}$ decrease in core body temperature in humans, the hematocrit reportedly increases by $2 \%$ (Harnett et al. 1980). Erythrogram indices were not identified as predictors of survival, presumably due to confounding effects from hemodynamic changes such as hemoconcentration, thus likely masking anemia and hypoproteinemia, and distorting trends. For this reason, anemia is clinically suspected when hematocrit data are within ranges in a hypothermic human patient (Mallet 2002). Hypothermia can also cause bone marrow suppression, erythroid hypoplasia, and sideroblastic anemia (O'Brien et al. 1982, Rosenkranz 1985). CSS humans and manatees have demonstrated a predisposition to bleeding secondary to hypothermia-induced DIC (Mallet 2002, Barratclough et al. 2017a). In the present study, pulmonary and dermal intravascular thrombosis and intrapulmonary hemorrhage were observed in CSS manatees. Furthermore, mechanisms of anemia of inflammatory disease may also contribute to changes in hematocrit, as previously described (Reidarson 2008).

Rubricytosis in the absence of anisocytosis and polychromasia was consistently evident in CSS manatees, which is consistent with inappropriate rubricytosis. This is in contrast to rubricytosis with anisocytosis and polychromasia as part of an adequate erythroid regenerative response. Inappropriate rubricytosis has been associated with hypothermia effects on bone marrow, including hypoxia, systemic inflammation, and/or necrosis (O'Brien et al. 1982, Rosenkranz 1985, Harvey 2012). In a study of hypothermic dogs, circulating nucleated erythrocytes were detected during the early rewarming period (Villalobos et al. 1955). Therefore, rewarming may result in release of metarubricytes in CSS manatees affected by any degree of severity, possibly through reperfusion and endothelial damage, since $\mathrm{nRBC}$ and NRBC were not identified as predictors of survival.

Serum proteins in CSS manatees changed as expected with inflammation. As in other studies, decreased albumin, in its function as a negative acute phase protein, and increased Glob and Alb:Glob ratio, are consistent with inflammation in CSS manatees (Bossart et al. 2002, Cray et al. 2013). Additional considerations for changes in albumin include renal or gastrointestinal loss secondary to hypothermiainduced injury as described in humans (McKean et al. 1970, Takeuchi et al. 1999). However, Alb, Glob, and the Alb:Glob ratio were not predictive of survival in CSS manatees. Previous studies of Alb:Glob ratios in manatees have documented methodology-specific variations (Harr et al. 2006, Harvey et al. 2007, Cray et al. 2013). Those studies have shown plasma protein electrophoresis to demonstrate high sensitivity and specificity for the diagnosis of inflammatory disease in manatees; however, other methodologies such as serum protein electrophoresis or, as in this study, chemistry analyzer methodology (e.g. bromcresol green for albumin), did not appear as sensitive or diagnostically useful. Albumin reportedly gets over-estimated with the bromcresol green method compared to plasma protein electrophoresis (Harvey et al. 2007). This limitation should be considered when interpreting biochemistry data from manatees. Fibrinogen was higher at admission than compared to release, although intake concentrations were still within the established reference ranges for the species (Harr et al. 2006). A decreasing trend with rehabilitation was seen and presumably due to resolving of ongoing inflammation, although clinically significant elevations of fibrinogen with CSS were lacking.

The clinical value of SAA as a prognostic indicator in CSS manatees was not demonstrated in this study despite higher concentrations at admission compared to pre-release. Previous studies of SAA in CSS manatees found a similar trend on initial bloodwork (Harr et al. 2006, Cray et al. 2013). Diagnostic testing of SAA in manatees with inflammation from various conditions have found SAA testing to be sensitive and specific for the diagnosis of inflammation, which appears consistent with the present study (Harr et al. 2006, Cray et al. 2013). However, a one-time SAA sample at admission did not demonstrate utility as a prognostic indicator for survival, suggesting variations similar to other inflammatory markers as discussed above. Based on the current and previous studies, following SAA trends in CSS manatees has potential as a monitoring tool (Harr et al. 2006, Cray et al. 2013), which notably applies to the rewarming phase. SAA increases with acute inflammation in horses, while other inflammatory markers such as fibrinogen typically predominate with chronic inflammation (Belgrave et al. 2013). Therefore, SAA may be more useful in acute CSS manatee cases compared to chronically affected animals, but further study is warranted to investigate this potential clinical application. An additional consideration for the lack of its utility as a prognostic indicator may stem from the observation that SAA reportedly decreases with increased endogenous glucocorticoids with chronic cold exposure in rats (Goundasheva et al. 1994). Free-ranging manatees may have a similar effect from increased corticosteroids resulting from handling during rescue and transport to rehabilitation facilities. 
Alterations in glucose homeostasis in CSS manatees manifested as hyperglycemia in $45 \%$ (25 of 56) of animals at admission, when comparing reference ranges of CSS manatees to those of healthy freeranging manatees (Bossart et al. 2001). Hypothermia modulates glucose by directly affecting the islets of Langerhans, while concurrently decreasing insulin secretion (Curry \& Curry 1970) and tissue sensitivity (Bernard et al. 2002). Another human study reported that hypothermic induction of the sympathetic nervous system causes catecholamine-induced glycogenolysis and gluconeogenesis (Stoner et al. 1980, Mallet 2002). In 2 CSS manatees of the present study, hepatic glycogenosis was recognized by histopathology. Serum glucose was not identified as a predictor of survival. In chronic cases of human hypothermia, glycogen stores reportedly tend to become depleted, likely due to excessive energy demand and concurrent anorexia, with consequent development of hypoglycemia (Mallet 2002). An additional possible confounding variable is stress-associated hyperglycemia from rescue, transport, or starvation sequelae.

Nitrogenous compounds in CSS manatees demonstrated clinically applicable information for underlying pathophysiological mechanisms and prognosis. A rising trend in Crea towards azotemia was evident during rehabilitation, although all values obtained were considered within normal limits for the species (Harvey et al. 2007). Comparing CSS manatee to healthy free-ranging manatee reference ranges, the initially lower Crea at admission in CSS manatees was likely due to starvation and/or malnutrition as identified in $78.5 \%$ of the animals (11 of 14) (Harvey et al. 2007). This is consistent with previous necropsy findings in CSS manatees in which emaciation, fat store depletion, and serous fat atrophy were common (Buergelt et al. 1984, Bossart et al. 2002). Serum Crea was not a predictor of survival. When admission Crea values were compared to healthy free-ranging manatees, the data were consistent with ranges found in healthy free-ranging manatees (Harvey et al. 2007). This may be due to opposing mechanisms with regards to Crea in CSS syndrome, ultimately resulting in normal ranges. While starvation tends to decrease Crea, other factors such as hemoconcentration or renal insufficiency can increase plasma concentrations. Hypothermia-induced diuresis is mediated by the inhibition of tubular reabsorption and resistance to the affects of vasopressin (Mallet 2002). In cases of moderate hypothermia $\left(27-30^{\circ} \mathrm{C}\right)$ in humans, significant reductions in the glomerular filtration rate is associated with decreased cardiac output (Mallet 2002). In the present study, 42.8\%
(6 of 14) of CSS manatees exhibited evidence of decreased cardiac output, such as hepatic chronic passive congestion (5 of 14) or myocardial edema (1 of 14).

Increased serum Crea may also result from acute renal failure as described in greater than $40 \%$ of human patients with accidental hypothermia-associated rewarming and ischemic renal damage (McKean et al. 1970). The significance is unknown in 3 animals with renal pathological lesions: 1 CSS manatee with grossly diffuse bilateral renal swelling (histopathological evaluation was not performed), another animal with renal interstitial fibrosis and tubuloproteinosis, and a third with bilateral glomerulopathy. In the present study, 1 CSS manatee had diffusely swollen kidneys which may have represented acute renal pathological lesions; however, histopathological evaluation was unavailable. Another manatee was diagnosed with renal interstitial fibrosis and tubuloproteinosis by histopathology. Previous studies of CSS manatees have documented dehydration as discussed above (Bossart et al. 2002) and as described with erythrogram and electrolyte changes in this study, with various mechanisms of fluid imbalances that appear to limit the utility of creatinine as a prognostic indicator.

BUN significantly differed between survivors and non-survivors, making it a useful prognostic indicator. Comparing CSS manatees to healthy freeranging manatee reference ranges, an approximately 5-fold elevated BUN was observed in $71 \%$ (5 of 7) of CSS non-survivors (CSS mean \pm SD: $8.35 \pm$ $5.0 \mathrm{mmol} \mathrm{l}^{-1}$, range $2.50-18.20 \mathrm{mmol} \mathrm{l}^{-1}$ vs. healthy mean $2.1 \mathrm{mmol} \mathrm{l}^{-1}$, range $0.4-4.3 \mathrm{mmol} \mathrm{l}^{-1}$ ) (Harvey et al. 2007). Elevated BUN in CSS manatees can be consistent with prerenal azotemia secondary to coldinduced diuresis and hemoconcentration, and/or gastrointestinal hemorrhage as reported in CSS humans (Mallet 2002). Other studies have demonstrated hypothermic induction of gastric acid production and decreased duodenal bicarbonate secretion, leading to gastric and duodenal mucosal damage with CSS (Takeuchi et al. 1999, Mallet 2002). In human CSS cases, punctate hemorrhages or ulcerations can occur throughout the gastrointestinal tract, and can demonstrate a characteristic appearance in the stomach termed Wischnewski spots (Reuler 1978, Bright et al. 2013). These distinctive areas of hemorrhage are considered the most reliable indicator of significantly reduced core body temperature in humans (Bright et al. 2013). In the present study, $64.3 \%$ (9 of 14) of CSS manatees had evidence of gastrointestinal ulceration and/or hemorrhage. The 
characteristic mucosal lesions were observed in the greater curvature of the stomach and duodenum (9 of 14) and some appeared to visually resemble Wischnewski spots (Birchmeyer \& Mitchell 1989, Çetýn et al. 2015). Two other studies evaluating CSS manatee necropsy data reported enterocolitis in 50\% (6 of 12) (Bossart et al. 2002) and 40\% (4 of 10) (Bossart et al. 2004) of manatees, although further detail regarding the specific gastrointestinal pathological lesions and ulcerations was not described. In the present study, $75 \%$ (3 of 4) CSS manatees with gastric ulceration and available concurrent ante-mortem blood work data had clinically elevated BUN (>7.14 mmol $\mathrm{l}^{-1}$ ). Rehabilitating CSS manatees with elevated BUN may not only be azotemic but also may have gastrointestinal hemorrhage. This is clinically significant since CSS manatees may benefit from presumptive treatment for gastrointestinal ulcerations. An increased BUN:Crea ratio was seen on admission blood data. However, the contrasting mechanisms of dehydration and starvation leading to Crea variations may have confounding effects on the clinical use of the BUN:Crea ratio.

Electrolyte changes further confirmed the presence of hemodynamic derangements in CSS manatees. Cold temperatures reportedly reduce renal tubular function causing diuresis and natriuresis in humans (MacLean \& Emsile-Smith 1977, Hamlett 1983). Although $\mathrm{Na}$ and $\mathrm{Cl}$ did not differ between surviving and non-surviving manatees, alterations in $\mathrm{Na}$ and $\mathrm{Cl}$ at admission were clinically mild presumably from similar mechanisms as discussed for hemoconcentration.

Ca homeostasis was substantially affected in CSS manatees as emphasized by its identification as a predictor of survival. Ca was found to be lower at admission in CSS manatees, which is similar to observations in hypothermic humans in which hypocalcemia has been associated with electrolyte shifts into intracellular space (Scaravilli et al. 2012). In humans, one of the resulting consequences during hypothermia and rewarming is neuron necrosis and possible brain tissue injury (Warren et al. 2012). Such pathophysiology has been noted as one of the significant detrimental effects of hypothermia, and may be the reason Ca was a prognostic indicator for survival in CSS manatees (Jo et al. 2014). In addition, lower serum Ca in non-surviving CSS manatees may result from renal or gastrointestinal damage (McKean et al. 1970, Mallet 2002). Necropsy data of the non-survivor manatees in the present study also revealed gastrointestinal ulceration and renal pathological lesions in $64.3 \%$ (9 of 14) and $21.4 \%$ (3 of 14) of man- atees, respectively. Cold-induced diuresis due to decreased renal tubular function may be an additional consideration for the decreased Ca. All of these considerations highlight the clinical significance of $\mathrm{Ca}$ and its potential systemic effects in CSS manatees.

A decreasing trend in $\mathrm{P}$ was evident with rehabilitation, and likely reflects correction of acid-base and renal derangements. Increased $\mathrm{P}$ can be seen with metabolic and respiratory acidosis with hypothermia due to decreased tissue perfusion, lactate generation, and impaired hepatic metabolism and acid secretion (Miller et al. 1980). Renal insufficiency generally results in hyperphosphatemia. Acute renal failure was identified in greater than $40 \%$ of hypothermic patients, which is thought to be associated with the rewarming phase (McKean et al. 1970). In the present study, 3 animals exhibited renal pathological lesions: 1 CSS manatee with grossly diffuse bilateral renal swelling (histopathological evaluation was not performed), another animal with renal interstitial fibrosis and tubuloproteinosis, and the third with bilateral glomerulopathy. Hyperphosphatemia may also represent pre-renal azotemia due to hypothermia-induced diuresis, or secondary to muscle damage from ischemia, hypoxia, and/or thrombosis. In the present study, muscle pathological lesions were identified in $35.7 \%$ (5 of 14) of CSS manatees, as evidenced by myositis, muscle necrosis, or abscessation. The muscle necrosis prevalence may be underrepresented, as histopathological evaluation was only performed on grossly identified abnormal tissue.

Tissue enzyme changes with increased activities at admission were reflective of tissue damage as expected in CSS manatees. This is consistent with reports in humans with hypothermia and associated non-specific tissue injury due to free-radical generation, ischemia, and macro- and microvascular thrombosis in many organs (Mallet 2002, Mills 2002). AST is found in many tissues in mammals; therefore, the mild elevation in CSS manatees may represent cellular damage affecting heart, liver, skeletal muscle, kidney, spleen, and/or lung. Muscle injury was also evident by increased LDH, CK, and AST, in addition to the above discussed $\mathrm{P}$, and may be a consequence of hypothermia-mediated hypoxia and lactic acidosis due to reduced tissue perfusion from vasoconstriction or thrombosis. In the present study, muscle pathological lesions (myositis, abscesses, or necrosis [6 of 14]), and intravascular thrombosis (dermal [6 of 12] and pulmonary [1 of 12]) were documented by histopathology. Elevated AST activity was identified as a predictor of survival in CSS manatees. The magnitude of AST increase may be correlated with the 
severity of hypothermia-induced cellular damage. In addition to skeletal muscle, AST can be found in high concentrations in cardiac muscle. A previous study of CSS manatee necropsy evaluations identified $58 \%$ of manatees with evidence of myocardial degeneration, although the significance of cardiac lesions was unknown given the lack of finding concurrent cardiac decompensation (Bossart et al. 2002). In the present study, 5 manatees had evidence of cardiac pathological lesions and decompensation as indicated by hepatic chronic passive congestion in all 5 manatees and additional myocardial edema in 1 manatee. Specific findings in individual manatees included cardiomyocyte atrophy in conjunction with pulmonary edema, cardiomyocyte lipofuscin accumulation, and possible endothelial thrombi in conjunction with hepatic congestion, and myocyte necrosis with hepatic acute passive congestion and myocardial edema.

A decreasing trend in GGT was observed in survivors over the course of rehabilitation. Potential causes for increased GGT in the CSS manatees include hypotension and hypoxia in liver tissue, which may be a consequence of blood loss associated with DIC or hypovolemia-induced diuresis secondary to hypothermia (Ettinger \& Feldman 2005). Therefore, correction of dehydration, hypovolemia, or hypotension over the course of rehabilitation is consistent with the GGT trends identified in CSS manatees. It is interesting to note that in hypothermic humans, vacuolar hepatopathy is well-described, and was also identified in 2 CSS manatees in this study, one of which demonstrated increases in cholesterol and GGT (Madea et al. 2008)

Although full blood gas analysis was not available, measured serum $\mathrm{CO}_{2}$ in $\mathrm{CSS}$ manatees indicates evidence of underlying blood gas abnormalities. Specifically, lower $\mathrm{CO}_{2}$ was evident on intake when compared to pre-release blood data of surviving manatees. In human hypothermia, respiratory alkalosis is seen due to hypothermic reduction in $\mathrm{CO}_{2}$ production (Reuler 1978) or with mild hypothermia due to the induction of tachypnea (Bernard \& Buist 2003). Hypothermia also alters blood gas solubilization, with each decreasing ${ }^{\circ} \mathrm{C}, \mathrm{pH}$ increases by 0.015 , and $\mathrm{pO}_{2}$ and $\mathrm{pCO}_{2}$ decrease by 7.2 and $4.4 \%$, respectively (Reuler 1978). Since our data may have been confounded by transport of manatees and delay in sample analysis, further investigation of blood gas analysis in CSS manatees is warranted.

Lipid metabolism was also affected in CSS manatees. Increased Chol and Trig were identified on intake blood work in CSS manatees. Hypothermic humans with core body temperatures between 30 and $35^{\circ} \mathrm{C}$ reportedly have increased fat mobilization reflected in raised plasma lipids (Polderman 2004). Additionally, a negative energy balance has been well described in horses for increasing plasma lipids and would appear consistent with CSS manatees based on this study (McKenzie 2011). The present study demonstrated emaciation and depletion of fat stores in $85.7 \%$ of animals, which is consistent with previous findings in CSS (Bossart et al. 2002). Two of 14 manatees in the present study had vacuolar hepatopathy characterized by lipid accumulation, which has also been documented in hypothermic humans (Madea et al. 2008) and further supports lipid mobilization. Therefore, increased mobilization of fat stores from hypothermia and prolonged anorexia are likely significant contributors to changes in serum Chol and Trig. Nutritional support during rehabilitation likely accounts for the decreasing trend in these analytes during rehabilitation

\section{CONCLUSIONS AND CLINICAL RELEVANCE}

This study highlights the complexity of clinicopathological derangements in CSS manatees. The results of the clinicopathological analysis, interpreted in conjunction with the anatomic pathological findings, demonstrate that hypothermia-induced diuresis, fluid imbalances, bone marrow damage, negative energy balance, gastrointestinal ulceration, tissue necrosis, hepatic impairment, and acid-base disturbances play significant roles in CSS pathophysiology. The identified prognostic indicators BUN, Ca, platelets, and AST, interpreted in light of the anatomic pathological features in CSS manatees, reveal that multi-organ tissue injury, gastrointestinal ulceration and/or hemorrhage, hemodynamic and platelet derangements are the presumptive major factors involved in mortality of CSS manatees. Supportive medical care directed at mitigating these pathological disturbances is likely integral to successful rehabilitation of CSS manatees. The results of this study contribute to the understanding of the complex CSS pathophysiology and may facilitate improvements in the medical care of CSS manatees using blood data for monitoring and prognosis during rehabilitation. The ultimate goals of the data and conclusions presented herein are the application as a clinical tool, inspiration for further studies, development of new treatment strategies, improved rehabilitation success, and contribution to the conservation of the Florida manatee. 
Acknowledgements. We thank the Florida Fish and Wildlife Conservation Commission and SeaWorld Orlando for their contributions to this project and their valiant efforts in coldstressed manatee rehabilitation and conservation. We are grateful to anatomic pathologists involved in reviewing histopathology samples used in this study, Dr. David Rotstein, Dr. Lisa Farina, and pathologists from the Zoological Pathology Program, Veterinary Diagnostic Laboratory, at the University of Illinois. This study was performed under the University of Florida's IACUC no. 201406823. Rescue and rehabilitation activities were conducted under the US Fish and Wildlife Service federal research permit no. MA770191.

\section{LITERATURE CITED}

Barratclough A, Ball RL, Francis Floyd R, Reep RL, Conner BJ (2017a) Proposal and application of a novel disseminated intravascular coagulation scoring system in the Florida manatee (Trichechus manatus latirostris). J Zoo Wildl Med 48:152-158

* Barratclough A, Conner BJ, Brooks MB, Pontes Stablein A and others (2017b) Identifying coagulopathies in the pathophysiology of cold stress syndrome in the Florida manatee Trichechus manatus latirostris. Dis Aquat Org 125:179-188

* Belgrave RL, Dickey MM, Arheart KL, Cray C (2013) Assessment of serum amyloid A testing of horses and its clinical application in a specialized equine practice. J Am Vet Med Assoc 243:113-119

Bernard SA, Buist M (2003) Induced hypothermia in critical care medicine: a review. Crit Care Med 31:2041-2051

* Bernard SA, Gray TW, Buist MD, Jones BM, Silvester W, Gutteridge G, Smith K (2002) Treatment of comatose survivors of out-of-hospital cardiac arrest with induced hypothermia. N Engl J Med 346:557-563

* Birchmeyer MS, Mitchell EK (1989) Wischnewski revisited: the diagnostic value of gastric mucosal ulcers in hypothermic deaths. Am J Forensic Med Pathol 10:28-30

Bossart GD (2001) Manatees. In: Dierauf LA, Gulland FMD (eds) Marine mammal medicine. CRC Press, Boca Raton, FL, p 939-960

Bossart GD, Reidarson TH, Dierauf LA, Duffield DA (2001) Clinical pathology. In: Dierauf LA, Gulland FMD (eds) Marine mammal medicine. CRC Press, Boca Raton, FL, p 383-435

* Bossart GD, Meisner RA, Rommel SA, Ghim S, Jenson AB (2002) Pathological features of the Florida manatee cold stress syndrome. Aquat Mamm 29:9-17

* Bossart GD, Meisner RA, Rommel SA, Lightsey JD, Varela RA, Defran RH (2004) Pathologic findings in Florida manatees (Trichechus manatus latirostris). Aquat Mamm 30:434-440

Bright F, Winskog C, Walker M, Byard RW (2013) Why are Wischnewski spots not always present in lethal hypothermia? The results of testing a stress-reduced animal model. J Forensic Leg Med 20:785-787

'Buergelt CD, Bonde RK, Beck CA, O'Shea TJ (1984) Pathologic findings in manatees in Florida. J Am Vet Med Assoc 185:1331-1334

* Çetýn S, Ýnanir NT, Eren F, Eren B, Dokgöz H (2015) Wischnewsky [sic] spots in fatal hypothermia. Case Rep Med 10:280-282

K Cray C, Rodriguez M, Dickey M, Brewer LB, Arheart KL (2013) Assessment of serum amyloid A levels in the reha- bilitation setting of the Florida manatee (Trichechus manatus latirostris). J Zoo Wildl Med 44:911-917

* Curry DL, Curry KP (1970) Hypothermia and insulin secretion. Endocrinology 87:750-755

Dembek KA, Hurcombe SD, Frazer ML, Morresey PR, Toribio RE (2014) Development of a likelihood of survival scoring system for hospitalized equine neonates using generalized boosted regression modeling. PLOS ONE 9:e109212

* Deng H, Han HS, Cheng D, Sun GH, Yenari MA (2003) Mild hypothermia inhibits inflammation after experimental stroke and brain inflammation. Stroke 34:2495-2501

Deutsch C (2008) Trichechus manatus ssp. latirostris. The IUCN Red List of Threatened Species. www.iucnredlist. org/ (accessed 26 April 2018)

Ettinger S, Feldman EC (2005) Textbook of veterinary internal medicine, 6th edn. W.B. Saunders Company, St. Louis, MO

Goundasheva D, Andonova M, Ivanov V (1994) Changes in some parameters of the immune response in rats after cold stress. Zentralbl Veterinärmed Reihe C 41:670-674

Greiner M, Pfeiffer D, Smith RD (2000) Principles and practical application of the receiver-operating characteristic analysis for diagnostic tests. Prev Vet Med 45:23-41

Hamlett M (1983) The fluid shifts in hypothermia. In: Pozos $\mathrm{R}$, Wittmers L (eds) The nature and treatment of hypothermia. University of Minnesota Press, Minneapolis, MN, p 94-99

Harnett RM, Pruitt JR, Sias FR (1983) A review of the literature concerning resuscitation from hypothermia, I: the problem and general approaches. Aviat Space Environ Med 54:425-434

*Harr K, Harvey J, Bonde R, Murphy D and others (2006) Comparison of methods used to diagnose generalized inflammatory disease in manatees (Trichechus manatus latirostris). J Zoo Wildl Med 37:151-159

Harvey JW (2012) Veterinary hematology: a diagnostic guide and color atlas. Elsevier Saunders, St. Louis, MO

*Harvey JW, Harr KE, Murphy D, Walsh MT and others (2007) Clinical biochemistry in healthy manatees (Trichechus manatus latirostris). J Zoo Wildl Med 38: 269-279

*Harvey JW, Harr KE, Murphy D, Walsh MT and others (2009) Hematology of healthy Florida manatees (Trichechus manatus latirostris). Vet Clin Pathol 38:183-193

* Irvine AB (1983) Manatee metabolism and its influence on distribution in Florida. Biol Conserv 25:315-334

Jo YH, Kim K, Lee JH, Rim KP, Cho IS (2014) Rapid rewarming after therapeutic hypothermia worsens outcome in sepsis. Clin Exp Emerg Med 1:120-125

Kurth J (2017) Endangered and threatened wildlife and plants; reclassification of the West Indian manatee from endangered to threatened. Federal Register. Rules and Regulations 82 Fed. Reg. 64 (April 5, 2017)

MacLean D, Emslie-Smith D (1977) Accidental hypothermia. JB Lippincott, Philadelphia, PA

Madea B, Tsokos M, Preuß J (2008) Death due to hypothermia: morphological findings, their pathogenesis and diagnostic value. Forensic Pathol Rev 5:3-21

Mallet ML (2002) Pathophysiology of accidental hypothermia. QJM 95:775-785

*McKean WI Dixon SR, Gwynne JF, Irvine RO (1970) Renal failure after accidental hypothermia. BMJ 2:463-464

*McKenzie HC III (2011) Equine hyperlipidemias. Vet Clin N Am Equine Pract 27:59-72

*Mikhailidis DP, Hutton RA, Jeremy JY, Dandona P (1983) 
Hypothermia and pancreatitis. J Clin Pathol 36:483-484 Miller JW, Danzl DF, Thomas DM (1980) Urban accidental hypothermia: 135 cases. Ann Emerg Med 9:456-461

Mills W (2002) Clinical aspects of freezing cold injury. In: Pozos R (ed) Medical aspects of harsh environments, Vol 1. Office of the Surgeon General, US Army, Washington DC, p 429-466

O'Brien H, Amess JAL, Mollin DL (1982) Recurrent thrombocytopenia, erythroid hypoplasia and sideroblastic anaemia associated with hypothermia. Br J Haematol 51: 451-456

Polderman KH (2004) Application of therapeutic hypothermia in the intensive care unit. Intensive Care Med 30: 757-769

Reidarson T (2008) Inflammation in marine mammals. In: Fowler M, Miller E (eds) Zoo and wild animal medicine, 6th edn. Current therapy. Saunders Elsevier, St. Louis, MO, p 308-311

Reuler JB (1978) Hypothermia: pathophysiology, clinical settings, and management. Ann Intern Med 89:519-527

Rosenkranz L (1985) Bone marrow failure and pancytopenia in two patients with hypothermia. South Med J 78: 358-359

Scaravilli V, Bonacina D, Citerio G (2012) Rewarming: facts and myths from the systemic perspective. Crit Care 16(Suppl 2):A25

Stacy NI, Innis CJ, Hernandez JA (2013) Development and evaluation of three mortality prediction indices for cold-

Editorial responsibility: Michael Moore,

Woods Hole, Massachusetts, USA stunned Kemp's ridley sea turtles (Lepidochelys kempii). Conserv Physiol 1:cot003

Stoner HB, Frayn KN, Little RA, Threlfall CJ, Yates DW, Barton RN, Heath DF (1980) Metabolic aspects of hypothermia in the elderly. Clin Sci (Lond) 59:19-27

Takeuchi K, Suzuki K, Araki H, Mizoguchi H, Sugamoto S, Umdeda M (1999) Roles of endogenous prostaglandins and nitric oxide in gastroduodenal ulcerogenic responses induced in rats by hypothermic stress. J Physiol Paris 93: 423-431

Valeri CR, Cassidy G, Feingold H, Ragno G, Khuri S, Altschule MD (1987) Hypothermia-induced reversible platelet dysfunction. Ann Surg 205:175-181

Villalobos TJ, Adelson E, Barila TG (1955) Hematologic changes in hypothermic dogs. Proc Soc Exp Biol Med 89: 192-196

*Walsh CJ, Luer CA, Noyes DR (2005) Effects of environmental stressors on lymphocyte proliferation in Florida manatees, Trichechus manatus latirostris. Vet Immunol Immunopathol 103:247-256

* Warren DE, Bickler PE, Clark JP, Gregersen M, Brosnan H, Mckleroy W, Gabatto P (2012) Hypothermia and rewarming injury in hippocampal neurons involve intracellular $\mathrm{Ca}^{2+}$ and glutamate excitotoxicity. Neuroscience 207:316-325

* Yoshihara H, Yamamoto T, Mihara H (1985) Changes in coagulation and fibrinolysis occurring in dogs during hypothermia. Thromb Res 37:503-512

Submitted: August 3, 2018; Accepted: October 16, 2018 Proofs received from author(s): December 4, 2018 